Article

\title{
Towards Urban Resilience through Inter-City Networks of Co-Invention: A Case Study of U.S. Cities
}

\author{
Der-Shiuan Lee \\ Department of Urban Planning and Development Management, Chinese Culture University, \\ Taipei 11114, Taiwan; ldx2@g.pccu.edu.tw; Tel.: +886-2-2861-1801 (ext. 41121)
}

Received: 22 December 2017; Accepted: 16 January 2018; Published: 24 January 2018

\begin{abstract}
Knowledge creation involves social and collaborative processes with local and extra-local partners. The space of knowledge flows functions as a system of networks where knowledge is transmitted around different alignments of agents in distant places. Scholars argue that the concept of urban resilience combines local and extra-local competencies to develop an inter-city system, this is a major strategy for cities to mitigate and adapt to climate change and economic recession. Little attention has been given to the role of networks in co-invention and few empirical studies have been conducted. This article provides insights into the structure of inter-city networks of co-invention by examining the relative importance of the network compared with spatial proximity in biotechnology co-patenting across 150 American cities from 1983 to 2013 . Results show that the U.S. inter-city structure gradually becomes more explicit, apparent, and identifiable in the network-based system. Network proximity better defines the biotechnology co-patenting relationships among the U.S. cities compared with spatial proximity. The current inter-city networks of co-invention are mostly regional, with some national but few local ties. This structure provides a way to develop mitigation and adaptation policies for climate disasters or economic recessions.
\end{abstract}

Keywords: urban resilience; co-invention; network; proximity; knowledge exchange; biotechnology; patent

\section{Introduction}

Regional differences in innovative activity are generally of concern to economic geographers. Dissimilarities are mostly interpreted by localized knowledge spillovers, which argue that knowledge is spatially sticky and difficult to move outside clusters. In this environment, geographical proximity of economic agents promotes information sharing, learning, and exchange. Innovation processes within geographical clusters, tied to localized knowledge flows, have been extensively documented and are widespread across the U.S. and Europe [1-5]. While these empirical studies are remarkable in their geography scheme, information exchange develops in wide-ranging and long-distance networks of collaboration through formal and informal relationships [6-12]. Breschi and Lissoni [13] pointed out that knowledge exchange is not restricted to local networking in clusters only, but can also be distributed to distant areas via a variety of interactions [7,14]. This is highly evident in dynamic technologies such as in the biotechnology industry, where interactive processes of research and development have become crucial for inventive productivity [14-17]. Bathelt et al. [18] pointed out that local milieu need to establish connections with external sources of knowledge to infuse new ideas into the milieu. By collaborating, scientists and researchers in different areas can develop knowledge exchanges vicariously through perceptions and opinions in pursuit of corporate goals. Rondé and Hussler [6] concluded that working with collaboration local and extra-local partners and combining their techniques and complementary skills is considered to be a crucial strategy for cities evolving in a 
dynamic environment that requires rapid adaptation, while avoiding negative lock-in $[19,20]$. This has been shown in empirical studies of inter-firm, inter-city, or inter-region networks [21-27].

Based on the consensus described above, the complexity of urban systems and the uncertainty of climate impacts necessitates finding asks for new ways of using a wide range of knowledge to assess risks and take adaptation actions [28]. The notion of urban resilience is gaining prominence as climate change will impact on social, economic, and environmental systems and shape prospects for sustainable development. The most pressing issue of climate change is industry and economic decline [28-32]. Although there is no universal agreement on the definition and measurement of urban resilience, a broad consensus is that cities have to be resilient to minimize the effects of disasters and reduce economic losses, in order to maintain or develop new growth paths [30,33,34]. Balland et al. [26] studied the urban resilience of U.S. cities from 1975 to 2002 and found some cities have difficulties in dealing with industrial decline or climate change, while others reorganize resources, and this enables them to enter into a new notch. Nevertheless, the concept of urban resilience is still under development. Boschma [35] mentioned three dimensions of related work: the resilience of urban areas [36], the renewal of industrial systems from path dependency [37-39], and, most importantly, the structural conditions of innovation networks [26,30,40,41]. He argued that proximity between economic agents favors the formation of knowledge network ties. A combination of local linkages and global connections is advantageous for the evolution of urban resilience [18,19,35]. Crespo et al. [42] studied the role of knowledge networks to further understand tensions and conflicts in adaptive systems between connectedness. The underlying networks of knowledge exchange are therefore a substantial element of urban resilience [42]. The integration of inter-city knowledge networks and aspatial proximity causes in comprehending the new geography of innovation and urban resilience. Related studies describe innovative environments prevailing over local inventive structures, research resources, skilled professionals, founding opportunities, and extra-local corporate alliances, in coping with industrial and market decline [43-48]. An increasing numbers of U.S. cities with productive inventors justifies a complementary focus on a network-based system with an emphasis on the nature and strength of inter-city networks of inventor ties. Connections among inventors in different cities can serve as channels for new ideas and alternative perspectives to infuse into a city, building its urban resilience. However, in the literature on urban resilience, little attention has been paid to the structural properties of networks and few empirical studies have yet been conducted, especially in American cities. My previous work uncovered the role of network proximity among U.S. cities by comparing only the patterns of biotechnology inventive activity in 1979 and 2009 [25]. This article builds on prior studies by updating the database from 1983 to 2013 with a 10-year interval. It also extends the analysis by examining the relative importance of the network compared with spatial proximity in U.S. inter-city relationships. The objective of the article is to share some insights into the evolutionary perspective of American inter-city networks of co-invention, which provides useful information on the structural conditions of networks for urban resilience.

I spotlight co-patenting as an indicator of output in co-inventing because I see the links forged by inventors in the act of co-patenting as possible channels for intensive knowledge exchange. This is the case particularly in biotechnology co-patenting because technological advancement in the field involves the deepening of collaboration and the broadening of inventor relationships [7,14-16,24,25,44,45,49-51]. The inter-city networks of co-invention are formed by inventors' co-patenting ties and are ascribed to their connections to the cities where they reside $[14,16,24,25]$. I focus on U.S. cities because co-patenting has been a predominantly urban phenomenon in this country from the 19th century until now. Some empirical studies have confirmed that American cities are the top urban setting for the co-patenting process [24-27,52,53]. The four chosen years (1983, 1993, 2003, and 2013) roughly coincide with the important advances in information and communication technologies (ICTs) that are most likely to influence the U.S. network-based system. Initiating the analysis in 1983 captures the start of the personal computer (PC) age. The rise of e-mail and PC networking occurred around 1993, popular web search engines (e.g., Yahoo and Google) were popularized to obtain information 
in 2003, and the emerging momentum of the Internet of Things (IoT) around 2013 was propelled by the proliferation of internet-connected objects. I focus on U.S. cities as centers of knowledge creation and argue urban resilience is the capacity of a system to absorb and recover from the occurrence of hazardous events, in order to maintain the city's level of knowledge creation and innovation over the long-term [26]. Both exploratory spatial data analysis (ESDA) and methods of social network analysis were empirically conducted.

The remainder of the article is structured as follows. Section 2 reviews the literature on knowledge, proximity, and network-based systems. Section 3 proposes a framework for inter-city networks of co-invention that I apply in the analysis. Section 4 discusses the methods of spatial and network dependencies used to investigate inventors' relationships across urban systems. Section 5 introduces the data used and presents descriptive tabulations. Section 6 presents the results, showing the differences between network and spatial dependencies of biotechnology co-invention across the U.S. cities. Section 7 concludes the article by summarizing and considering future research directions.

\section{Knowledge, Proximity and Network-Based Systems}

Scholars have recognized that knowledge is key to urban and regional economic development. Nelson and Winter [54] initiated economic interest in how tacit knowledge exchange shapes technological advancement. Maskell and Malmberg [55] noted that tacit knowledge, including personal skills and know-how, is an important determinant of creation and invention. Interpersonal knowledge flows that are restricted in space influence local invention through interactive learning [14]. Gertler [56] argued that the transfer of tacit knowledge requires extensive communication and trust, which makes it spatially sticky. Information exchange appears locally between near individuals or within social groups who have common cultural, social, or language characteristics. Moreover, the nature of dynamic invention involves intensive efforts of collective sharing, learning, and understanding. Spatial proximity makes this kind of interaction much easier and more effective.

Acs et al. [2] and Audretsch and Feldman [3] reported indirect evidence of localized knowledge flows by investigating geographical variability in patents and innovation counts, and found that localized spillovers occur from university research. Jaffe [1] contended that industrial patents arising from university research lead to commercial innovation via knowledge spillovers conducted in the same American state. Acs et al. [57] also showed similar agglomeration advantages in analysis of innovation counts. By estimating knowledge production functions with geographical dependence methods, they explicitly weighed the influence of industrial and university research in neighboring areas [56,58]. A more direct approach traces locational biases in patent citation patterns $[53,59,60]$. Disproportionately citing the patents from nearby inventors suggests intense knowledge flows are locally circulated.

Extra-local relationships are influenced by the 'relational turn' in economic geography [18,61,62], which responds to greater awareness of the social, cultural, and ethnic dimensions of economic systems in different places and how these attributes shape complex relationships among diverse economic agents $[11,12,63]$. It concerns the ways in which social and cultural forces influence levels and growth of urban and regional economies [64]. Geography of invention requires interaction between local ties and extra-local connections that can provide supplemental technologies and skills $[14,19,20]$. Ideas and information exchanges are no longer fixed in space but increasingly span great distances. Maggioni et al. [7], Ponds et al. [17], Breschi and Lissoni [13,51], Gallaud and Torre [65], and Autant-Bernard et al. [66] all concluded that interactive learning and sharing spread widely via relational networks. Knowledge is not simply bounded in a cluster; there are considerable interactions with distant partners. Relevant phrases in the literature such as 'local buzz and global pipelines' [18,67], 'local nodes in global networks' [14,44], 'local sticky and global ubiquitous' [19], and 'local circuit and global circuit' [68] stress integral interfaces between local and extra-local knowledge exchange within and outside clusters, and stimulated studies of network proximity at a much wider range, comprising multiple cities rather than focusing on particular areas only $[69,70]$. The space of knowledge flows 
here is regarded as a kind of network-based system where knowledge circulates among economic agents through intra-cluster linkages and inter-city partnerships in different places [11,12]. Cities in such a sphere are immersed in a network where collaborative invention and innovation are decisive forces for urban resilience and technological advancement [30,40-43].

Access to external sources of knowledge is required to generate prosperous innovation and invention [14,70-77]. Creative firms build and sustain network-based systems where external and internal resources develop resilience capacity, in order to minimize the effects of disasters and reduce economic losses and therefore recover quickly from shocks [30,33,35,76]. Amin and Cohendet [11,12] argued that a network-based system is a disconnected geographical ecology of knowledge that could be held in place as relational knowledge. It is composed of relational ties between economic agents from different locations, allowing for the possibility of seeing a broad range of knowledge flows. This has two advantages. First, it holds knowledge to be place-specific for different markets where inventive activities are specifically aligned with the distinctive needs of local clients and customers [68]. Second, it translates varied ideas and practices into a corporate template where interactive learning takes place among agents through collaborative or other joint activities [69]. Cooke [16] argued that some high-technology research centers serve as magnets for profit-seeking biotechnology firms because these research centers operate with relatively open science conventions. Such 'openness' in innovation may have certain 'club' characteristics in a network-based system where partner-cities enjoy knowledge flows and exchange with one another on a global scale. The adoption of advanced information and communication technologies (ICTs) increases access to external resources and global participation [77]. For example, prosperous firms in Silicon Valley are intensively tied to extra-local partners located in other regions or countries [78]. Technological invention increasingly needs relational ties among agents with supplementary know-how and supporting skills, in order to take effective action $[7,14,19,20]$. Information transmission in aspatial networks appears in the shifting alignments of inventors across space in pursuit of particular goals [11,12]. Research institutions and leading universities perform demanding roles in incubating biotechnology centers and networks $[16,47,79]$. Venture capital firms and start-up companies are also significant $[64,79,80]$. In short, the space of knowledge flows in biotechnology shows an intense concentration of co-inventive activities in a few global excellence centers. A high degree of network proximity links different cities and extends the scope and geography of cooperation and collaboration. Investigating the patterns of inter-city networks of co-invention provides useful insights into knowledge exchange in space.

\section{Framework of Inter-City Networks of Co-Invention}

Knowledge flows circulate in geography via various routes and in various forms. Cassi and Morrison [81] viewed co-patenting as being built on formal and bilateral relationships between inventors [24,82]. This article applies social networks to build the framework of inter-city networks of co-invention. Polanyi [83] argued that knowledge is embedded in inventors who reside in a city. Figure 1 shows the framework of inter-city networks of co-invention and the social networks of inventors [25]. The upper framework refers to a co-inventive region within city A to F, while all nodes from its social network counterpart signify the individual inventors who reside in these cities. Co-inventive activities are the ties between individual inventors. Several inventors have external partnerships with inventors located in distant cities, while a few only cooperate with locals. Social networks uphold and promote interaction and communication between inventors leading to possible co-inventive activities. In this article, the inventor-links form the structure of inter-city networks of co-invention. The nodes refer to the observed U.S. cities with varying intensities of co-patenting productivity, while the links refer to the strength of co-patenting ties between inventors located in any connecting cities. City $\mathrm{C}$ is directly linked to City A, D, and E, indirectly linked to City B, and has no linkage with City F. Individual inventors in City F only collaborate with locals. They are isolated from inventors in other cities. In this simple inter-city network-based system, City A and B are the mostly 
intensely tied because two of City A's inventors co-invent with an inventor in City B. No other pair of cities has more than one direct link with a particular inventor in another city.

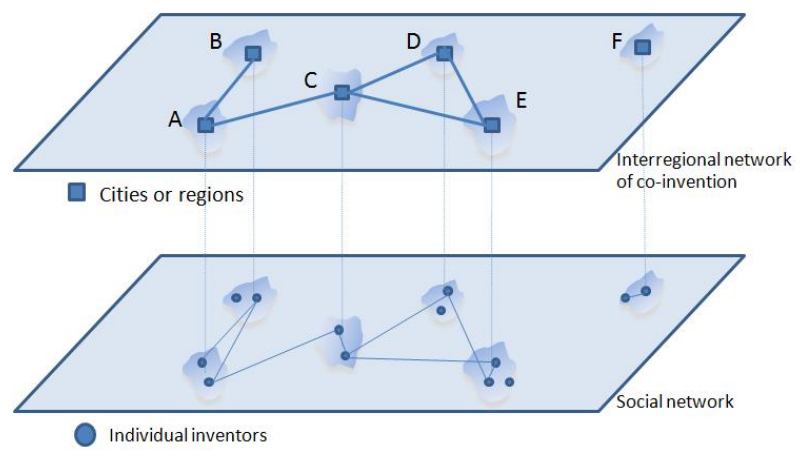

Figure 1. Social networks of inventors and inter-city networks of co-invention.

\section{Methodology}

The central question of this article is whether biotechnology co-invention reveals significant differences in network and spatial dependencies across the U.S. cities over time. The approach extends comparisons of both types of ties in European patents demonstrated by Maggioni et al. [7]. They identified stronger relational clusters in a subset of geographically distant excellence centers and concluded that the network-based systems are often stronger compared with those forged by spatial association. This article investigates knowledge flows by concentrating on co-patenting activity within and across U.S. biotechnology communities. I identify the differences between network and spatial dependencies across U.S. cities by comparing structures revealed in global- and local-level measures of dependencies. I argue cities are centers of knowledge creation where dynamic firms and inventors are located. A variety of internal and external resources develop the resilience capacity of a city in order to maintain or minimize the effects of disasters and reduce economic losses.

Each city's biotechnology co-inventing rate (or co-patenting rate) is calculated by dividing the city's annual co-patents by the number of wage and salary workers. Labor force and not total population is used to standardize co-patent counts because not all people generate inventions. As independent inventors account for a relatively small proportion of total patenting activity, especially in biotechnology [84], the number of wage and salary workers, which was retrieved from the U.S. Bureau of Economic Analysis [85], better relates co-inventive activity to potential inventors. The estimated biotechnology co-patenting rates of some cities with few inventors and rare co-patenting events may be spuriously identified as 'outliers' [86]. To compensate for co-patenting rate instability in small cities, original rates were smoothed using an Empirical Bayes Smoother [87]. The Geoda software package derived the statistics [88].

\subsection{Network and Spatial Dependencies at Global-Level}

I use the global Moran's I statistic as a measure to examine network and spatial dependencies in the inter-city networks of co-invention from 1983 to 2013 with a 10-year interval [26]. It is estimated by comparing each city's co-patenting rate with the co-patenting rates of the city's 'network' or 'spatial' neighbors. The global Moran's I statistic is defined as:

$$
I=\frac{m}{\sum_{i=1}^{m} \sum_{j=1}^{m} w_{i j}} \frac{\sum_{i=1}^{m} \sum_{j=1}^{m} w_{i j}\left(x_{i}-\bar{x}\right)\left(x_{j}-\bar{x}\right)}{\sum_{i=1}^{m}\left(x_{i}-\bar{x}\right)^{2}}
$$


where $m$ is the number of cities, $x_{i}$ and $x_{j}$ are the biotechnology co-patenting rates in cities $i$ and $j$, respectively; and $\bar{x}$ is the mean of the corresponding attributes in all $x$ values, and $w_{i j}$ is the 'network' or 'spatial' weight between feature $x_{i}$ and $x_{j}$. The explanation of the global Moran's I statistic is similar to the Pearson's correlation coefficient in that the statistics fall between +1 and -1 . When the statistic is positive, and the $p$-value is statistically significant, it indicates that cities with similar co-patenting rates, either low or high, are network-based or spatially located 'near' each other. In contrast, when the statistic is negative, and the $p$-value is statistically significant, it means that cities with dissimilar co-patenting rates are network-based or spatially located 'near' each other. When the statistic is equal to 0 , the overall structure is random, indicating that the U.S. inter-city co-invention is independent of either network or spatial dependence.

\subsection{Network and Spatial Dependencies at Local-Level}

The local Moran's I statistic of spatial association (also known as Anselin Local Moran's I) decomposes a global Moran's I statistic into the contribution of each city [88]. The tool calculates a statistic, a $p$-value, and a code representing the cluster type for each statistically significant feature. The Local Moran's I statistic is defined as:

$$
I_{i}=\frac{\left(x_{i}-\bar{x}\right)}{\frac{1}{m} \sum_{k=1}^{m}\left(x_{k}-\bar{x}\right)^{2}} \sum_{j=1}^{m} w_{i j}\left(x_{j}-\bar{x}\right)
$$

A positive statistic indicates that a city has neighboring cities with similarly high or low co-patenting rates; the city is identified as a 'network' or 'spatial' cluster. A negative statistic indicates that a city has neighboring cities with dissimilar co-patenting rates; the city is identified as an outlier. In either a cluster or an outlier, the $p$-value for the city shall be small enough so that the statistic can be considered statistically significant.

Anselin [89] developed 'local indicators of spatial association' (LISA) and implemented these as LISA cluster maps. A LISA cluster map discriminates between a cluster of high co-patenting rates (High-High), a cluster of low co-patenting rates (Low-Low), an outlier in which a high co-patenting rate is surrounded primarily by low co-patenting rates (High-Low), and an outlier in which a low co-patenting rate is surrounded primarily by high co-patenting rates (Low-High). The $p$-value is under 0.1 for statistical significance.

I follow Ó hUallacháin and Lee [24] and Lee [25] by distinguishing four possible patterns in a LISA cluster map, either network or spatial, along with non-significant areas.

- Co-inventive cores (High-High): there are clusters of high co-inventive cities. Co-patenting rates in the core cities are similarly high to their neighboring cities.

- Co-inventive peripheries (Low-Low): there are clusters of low co-inventive cities. Co-patenting rates in the peripheral cities are similarly low to their neighboring cities.

- High co-inventive islands (High-Low): there are cities with high co-patenting rates located in co-inventive peripheries. These outliers have dissimilar neighbors, as the weighted average of the neighbors' co-patenting rates is significantly lower than that of the island.

- Low co-inventive islands (Low-High): there are cities with low co-patenting rates located in co-inventive cores. These outliers have dissimilar neighbors, as the weighted average of the neighbors' co-patenting rates is significantly higher than that of the island.

- Non-significant areas: these are cities with non-significant local Moran's I statistics. The null hypothesis of randomness is not rejected. Co-patenting rates in these cities are not significantly similar to or different from co-patenting rates in their neighbors.

Network and spatial LISA cluster maps are generated to compare and contrast the network and spatial dependencies in the U.S. inter-city system from 1983 to 2013 with a 10-year interval. A co-inventive core is evident in the network LISA cluster map indicating that network proximity is 
important to the inter-city co-invention of inventors. In contrast, if the same neighbors compose a co-inventive core in a spatial LISA cluster map, co-patenting relationships of inventors are explained by spatial proximity. Moreover, the network LISA cluster map should appear for co-inventive core cities that are spatially scattered, as inter-city relationships often support co-patenting by inventors residing in dispersed cities $[25,90]$. A majority of low co-inventive islands occurring in the network LISA cluster map is assumed to be common because few national centers exist and most cities' linkages are confined to the regional nexus $[11,16,90]$.

\subsection{Network and Spatial Weights}

A critical step in network and spatial dependencies is to build weights matrices that contain the neighboring structures for each city. A network weights matrix $W_{n}$ is the annual frequency of co-patenting ties between inventors located in any two connecting cities. A co-patenting tie is established if inventors from different cities co-invent a patent. A higher frequency of different cities' inventors participating in co-patenting is associated with the existence of a stronger inter-city relationship. The original network weights matrix $W_{n}$ is dichotomized into a set of binary relations using the average frequency that cities are tied in co-patenting $[7,80]$. When the frequency of co-patenting ties between cities $i$ and $j$ is greater than or equal to an average-based cut-off point then $w_{i j}=1$, meaning that $i$ and $j$ are tied and recognized as neighbors; otherwise $w_{i j}=0$. In short, the network weights matrix takes the form of a square actor-by-actor binary adjacency matrix where the same set of U.S. cities is listed in both columns and rows. All elements within the network weights matrix $W_{n}$ indicate the nature and strength of the inter-city network of co-invention that facilitates knowledge exchange across the U.S. cities.

The spatial weights matrix $W_{s}$ defines the geographical features between each pair of cities. Owing to the wide variation in geographical spacing and the 'island' characteristic, this article uses the number of nearest neighbors (also known as an area's $k$ value) as the most appropriate choice to identify neighboring structures in the contiguous U.S. cities $[24,25,90]$. Numbers of cities ranging from three to 20 are considered to determine the appropriate number of nearest cities. I select the 10 nearest neighbors of all possible U.S. cities using the smallest $k$ value and the Monte Carlo simulations, in order to obtain the relative stable spatial LISA cluster maps. The 10 nearest neighbors delineate distinguishable spatial clusters.

\section{Patent Data and Geographical Units of Analysis}

The realm of biotechnology patents includes several classes of the U.S. patent classification (USPC) system. I follow Ó hUallacháin and Lee [24], Lee [25], Hall et al. [91], Cortright and Mayer [92], and Hevesi and Bleiwas [93] by selecting the 3-digit classes (424, 435, 514, and 800) into the sub-category of biotechnology. Class 435 covers chemical groupings and includes molecular biology and microbiology inventions. Class 800 encompasses multicellular living organisms, unmodified parts thereof, and related processes. Class 424 and Class 514 contain various drugs, bio-affecting compositions, and body-treating compositions [94]. All of the U.S. biotechnology co-patent data in 1983, 1993, 2003, and 2013 were retrieved from the patent citations data package in the U.S. National Bureau of Economic Research (NBER) [91] and the U.S. Patent and Trademark Office (USPTO) online database [94].

The geographical units of analysis are the selected U.S. cities. I particularly focus on the U.S. census-defined metropolitan statistical areas (MSAs) identified by the U.S. Office of Management and Budget in 1999 [95]. Metropolitan statistical areas are collections of counties that constitute integrated labor markets. Acs and Armington [96] argued that metropolitan areas ensure people both live and work within their boundaries. The 1999 definition identifies 275 metropolitan areas in the contiguous U.S. The uneven distribution of biotechnology patents across the U.S. MSAs leads us to discard small MSAs without any co-patented awards. In the article, the geographical units of analysis are reduced to 150 large MSAs, which I refer to as cities. A $150 \times 150$ symmetrical weights matrix, either network or spatial, is constructed for each chosen year of analysis. 
Each biotechnology patent shall have at least one inventor located in one of 150 cities. Patents invented by multiple inventors are separated from those by solo inventors. Foreign inventors are ignored, which confines the following study to domestic inter-city systems. I specify the geography of biotechnology co-patenting by attributing each co-patent to the locations where the inventors reside. A co-patent with multiple inventors living in different cities is fractionally allocated, which is consistent with Maggioni et al. [7], Ó hUallacháin and Lee [24], Lee [25], Ejermo and Karlsson [97]. If a co-patent was invented by three inventors residing in different cities, one-third of the co-patent is allotted to each city. Network calculations were collectively performed using the UCINET software for network analysis [98]. The wage and salary jobs were retrieved from the U.S. Bureau of Economic Analysis [85].

\subsection{Descriptive Statistics of Biotechnology Co-Patenting}

The biotechnology patents of each chosen year are split into two groups. Patents invented by multiple inventors are distinguished from solo inventors. Table 1 shows that patenting in biotechnology is gradually increasing. Co-patenting of biotechnology causes faster increases-from $54.37 \%$ in 1983 , $67 \%$ in 1993 , and $76.05 \%$ in 2003 , to $81.14 \%$ in 2013 . The time series for co-patenting team size (inventors per co-patent) also increased from 2.65 inventors in 1983, 3.12 in 2003, and 3.87 in 2013, to 4.74 in 2013.

Table 2 depicts the spatial realm of biotechnology co-patenting in the 150 U.S. cities. The trend reveals increasing inter-city co-patenting-from $17.1 \%$ in 1983 to $42.6 \%$ in 2013 , while most of the co-patenting activities occur locally (within the same city). In 1983, co-patenting activities rarely stretched beyond three cities. In 1993, the maximum co-patenting breadth extended to four cities. In 2003 and 2013, a few biotechnology co-patents linked inventors from five or more cities. An increasing number of cities are involved in co-patenting, leading to a wide range of extra-local links. Co-invention in biotechnology is broadening and deepening in the U.S. inter-city system.

Table 1. Number of U.S. biotechnology patents, 1983-2013.

\begin{tabular}{ccccc}
\hline & $\mathbf{1 9 8 3}$ & $\mathbf{1 9 9 3}$ & $\mathbf{2 0 0 3}$ & $\mathbf{2 0 1 3}$ \\
\hline Co-patents & 575 & 1672 & 5913 & 8973 \\
Solo patents & 482 & 835 & 1862 & 2085 \\
Total patents & 1057 & 2507 & 7775 & 11,058 \\
Co-patenting percentage & 54.39 & 67.00 & 76.05 & 81.14 \\
\hline
\end{tabular}

Note: Co-patenting percentage $=($ co-patents $/$ total patents $) \times 100$. Source: The NBER patent database [91] and The USPTO patent database [94].

Table 2. Spatial realm of biotechnology co-patenting, 1983-2013.

\begin{tabular}{ccccc}
\hline & $\mathbf{1 9 8 3}$ & $\mathbf{1 9 9 3}$ & $\mathbf{2 0 0 3}$ & $\mathbf{2 0 1 3}$ \\
\hline Intra-city co-invention & 82.9 & 77.5 & 68.7 & 57.4 \\
Co-patenting within the same city & 17.1 & 22.5 & 31.3 & 42.6 \\
Inter-city co-invention & 16.2 & 19.1 & 25.4 & 32.4 \\
Co-patenting across 2 cities & 0.9 & 2.8 & 4.7 & 7.5 \\
Co-patenting across 3 cities & 0 & 0.6 & 0.9 & 1.8 \\
Co-patenting across 4 cities & 0 & 0 & 0.3 & 0.9 \\
Co-patenting across 5 cities (or above) & 0
\end{tabular}

\subsection{Biotechnology Co-Patenting Productivity in Major U.S. Cities}

I prescribe co-patenting productivity for each city by attributing a biotechnology co-patent to the cities where the inventors reside. A co-patent with multiple inventors living in different cities is fractionally allocated. Table 3 shows the biotechnology co-patenting productivity in the top 30 U.S. cities ranked by 2013 data. In 2013, nearly 700 biotechnology co-patents were fractionally allocated in San Francisco, which stands out as the most prolific co-inventive center, followed by New York with 
546.6 co-patents, Boston with 447.2 co-patents, and Philadelphia with 368.4 co-patents. These four major centers accounted for more than $45 \%$ of the U.S. biotechnology co-patenting productivity. San Francisco and Boston established themselves as the leaders in biotechnology invention by the 1980s and continued to sustain their first-mover advantages [92]. New York and Philadelphia are the traditional centers of the pharmaceutical industry, particularly along the Northeast Corridor where many leading companies are headquartered. Inventors in San Diego (275.2 co-patents) and Washington D.C.-Baltimore (251.8 co-patents) have significantly increased their biotechnology co-patenting productivity. Cortright and Mayer [92] argued that San Diego is well known for its rapid growth of biological research over the past several years and has been particularly successful in "securing venture capital and research contracts with pharmaceutical firms" [92] (p. 14). The Washington D.C.-Baltimore metro area is home to several important research centers that facilitate biotechnology invention, including the National Institutes of Health (NIH) and the Biotechnology Industry Organization (BIO). Los Angeles (205.1 co-patents), Seattle (145.9 co-patents), Raleigh-Durham (130 co-patents), and Chicago (105.2 co-patents) rounded out the top 10 list of leading biotechnology co-patenting centers. Overall, the top 10 U.S. centers of biotechnology co-patenting productivity rising in rank contain major universities, strong technological infrastructure, and entrepreneurial cultures. For example, the University of Washington and research institutions in the nearby South Lake Union neighborhood were pivotal in the growth of Seattle's biotechnology cluster. A few small cities are also ranked in the top 30 of biotechnology co-patenting productivity including New Haven and New London (Connecticut), Rochester (New York), and Salt Lake City (Utah). The remaining cities have some co-patenting activities, but their levels are below the average (145.3 co-patents) of the top 30 cities in the sample.

Table 3. Biotechnology co-patenting productivity in the top 30 U.S. cities, 1983-2013.

\begin{tabular}{clcccc}
\hline \multicolumn{1}{c}{ Cities (MSAs, Ranked by 2013 Data) } & $\mathbf{1 9 8 3}$ & $\mathbf{1 9 9 3}$ & $\mathbf{2 0 0 3}$ & $\mathbf{2 0 1 3}$ \\
\hline 1 & San Francisco-Oakland-San jose, CA & 25.2 & 148.5 & 755.8 & 702.0 \\
2 & New York-Northern New Jersey-Long Island, NY-NJ-CT-PA & 144.3 & 374.1 & 698.2 & 546.6 \\
3 & Boston-Worcester-Lawrence, MA-NH-ME-CT & 8.8 & 69.3 & 488.2 & 447.2 \\
4 & Philadelphia-Wilmington-Atlantic City, PA-NJ-DE-MD & 66.8 & 147.4 & 447.9 & 368.4 \\
5 & San Diego, CA & 4.0 & 30.7 & 278.6 & 275.2 \\
6 & Washington D.C.-Baltimore, DC-MD-VA-WV & 11.5 & 50.5 & 360.8 & 251.8 \\
7 & Los Angeles-Riverside-Orange County, CA & 3.3 & 29.1 & 146.6 & 205.1 \\
8 & Seattle-Tacoma-Bremerton, WA & 0.0 & 25.2 & 110.9 & 145.9 \\
9 & Raleigh-Durham-Chapel Hill, NC & 3.8 & 26.2 & 107.2 & 130.0 \\
10 & Chicago-Gary-Kenosha, IL-IN-WI & 17.1 & 59.6 & 98.8 & 105.2 \\
11 & Madison, WI & 1.0 & 11.1 & 63.8 & 85.7 \\
12 & Denver-Boulder-Greeley, CO & 0.5 & 2.8 & 69.7 & 85.4 \\
13 & Des Moines, IA & 1.3 & 1.2 & 56.7 & 76.3 \\
14 & St. Louis, MO-IL & 8.8 & 13.9 & 77.5 & 73.5 \\
15 & New Haven-Bridgeport-Stamford, CT & 3.3 & 19.2 & 74.8 & 60.0 \\
16 & Minneapolis-St. Paul, MN-WI & 21.1 & 17.0 & 46.1 & 53.6 \\
17 & Indianapolis, IN & 20.5 & 50.8 & 112.5 & 50.4 \\
18 & Atlanta, GA & 1.0 & 6.4 & 29.1 & 47.2 \\
19 & Houston-Galveston-Brazoria, TX & 3.0 & 28.3 & 82.0 & 45 \\
20 & Dallas-Fort Worth, TX & 1.8 & 9.1 & 43.4 & 41.1 \\
21 & Detroit-Ann Arbor-Fllint, MI & 5.6 & 36.4 & 76.4 & 39.1 \\
22 & Rochester, NY & 7.7 & 26.5 & 26.3 & 23.3 \\
23 & Sacramento-Yolo, CA & 0.0 & 10.9 & 57.9 & 23.1 \\
24 & Hartford, CT & 0.3 & 6.3 & 23.3 & 22.6 \\
25 & Salt Lake City-Ogden, UT & 0.0 & 6.0 & 23.3 & 20.6 \\
26 & Portland-Salem, OR-WA & 1.5 & 2.2 & 16.0 & 20.5 \\
27 & Cincinnati-Hamilton, OH-KY-IN & 9.8 & 38.2 & 34.0 & 19.2 \\
28 & Pittsburgh, PA & 0.7 & 2.9 & 26.2 & 19.2 \\
29 & New London-Norwich, CT-RI & 6.5 & 18.8 & 37.3 & 19.0 \\
30 & Rochester, MN & 0.0 & 0.6 & 11.4 & 48.2 \\
\hline & Average of the top 30 cities & 17.5 & 50.0 & 164.4 & 145.3 \\
\hline
\end{tabular}

Source: The NBER patent database [91] and The USPTO patent database [94]. 


\section{Results and Discussion}

\subsection{Global-Level Dependence}

This article uses the global Moran's I statistic to detect the network and spatial dependencies in the inter-city co-invention of biotechnology from 1983 to 2013 with a 10-year interval. This statistic assesses the extent to which the overall structure exhibits a clustered, random, or dispersed configuration. It is calculated by comparing each city's co-patenting rate with the co-patenting rates of the city's 'network' or 'spatial' neighbors. Both network and spatial weights are constructed to indicate the different types of neighboring structures for each city.

The spatial weights matrix $W_{s}$ is selected $7 \%$ of the possible 150 cities, which yields the 10 nearest neighbors. The network weights matrix $W_{n}$ is constructed by using the average co-patenting ties in each chosen year as the cut-off point and converting the observed inter-city system into a set of binary relations. While average co-patenting ties vary over time, the cut-off point for the network weights matrix, the frequency of co-patenting ties, is 1.7 in 1983. If a city pair has two or more co-patenting ties, the weight is assigned a unity value and all other weights are assigned a 0 . In 1993, the cut-off point remains at two and the same rule is applied. In 2003, the co-patenting average rises to 2.9. All inter-city pairs with three or more co-patenting ties are assigned a unity weight; otherwise the weight is 0 . In 2013, the average co-patenting ties increases to 3.8 and inter-city pairs with four or more co-patenting ties are assigned a unity weight; otherwise the weight is 0 .

Table 4 shows the results of the global Moran's I statistics for cities' co-patenting rates. With pseudo significance values a permutation approach, only the 2013 network-based system shows a statistically significant but negative statistic $(I=-0.1235, p$-value $=0.009)$, meaning that cities with dissimilar attributes are networked closely with each other. The result from 2013 is consistent with my previous work [25], in which the U.S. cities with low co-patenting rates are network associated with major co-inventive centers. This evidence indicates that network proximity is developing in the U.S. inter-city system by connecting both major centers and minor cities.

Table 4. Global Moran's I statistics for cities' co-patenting rates, 1983-2013.

\begin{tabular}{ccccc}
\hline Type of Weights & $\mathbf{1 9 8 3}$ & $\mathbf{1 9 9 3}$ & $\mathbf{2 0 0 3}$ & $\mathbf{2 0 1 3}$ \\
\hline \multirow{2}{*}{ 10 nearest neighbors } & 0.0115 & -0.025 & -0.0247 & 0.0391 \\
& $(0.236)$ & $(0.471)$ & $(0.675)$ & $(0.285)$ \\
\hline \multirow{2}{*}{ Average-based cut-off point $=2$} & 0.0264 & 0.0124 & & \\
& $(0.147)$ & $(0.413)$ & & \\
\hline \multirow{2}{*}{ Average-based cut-off point $=3$} & & & 0.0476 & \\
& & & $(0.298)$ & \\
\hline \multirow{2}{*}{ Average-based cut-off point $=4$} & & & & -0.1234 \\
& & & & $(0.009)$ \\
\hline
\end{tabular}

Note: Numbers in parentheses are two-tailed significance levels. Source: Author's calculations.

Ó hUallacháin and Lee [24] demonstrated that the biotechnology co-patenting network in 2009 has a much denser structure than that of the 1979 network. Major co-inventive centers occupy pivotal positions in the U.S. inter-city system. For example, New York and San Francisco are primary co-inventive cores. Other large cities, including Los Angeles, San Diego, Seattle, Philadelphia, Chicago, and Boston, all have intense national and regional ties. As compared with my previous report [25], a significant and negative statistic indicates that the 2013 network proximity supports a trend of core underpinning and peripheral development $[99,100]$. In the inter-city networks of co-invention, biotechnology centers in the cores establish norms and conventions that inspire collective sharing and learning, while peripheral cities provide possible recruits who could access and absorb new ideas and fresh perspectives to prompt rapid adaptation and avoid negative lock-in, thus providing a way to build urban resilience $[19,20,24,35,42]$. 


\subsection{Local-Level Dependence}

The global Moran's I statistics mostly suggest that the U.S. inter-city system of co-invention is statistically non-significant in both spatial and network dependencies with the exception of the 2013 network-based result. A focus on local associations reveals useful details. Both the network and spatial LISA cluster maps identify local groupings and classify them into four patterns along with non-significant areas from 1983 to 2013 with a 10-year interval.

\subsubsection{Spatial Proximity}

Figure 2 shows the 1983 and 1993 spatial LISA cluster maps in the 150 U.S. cities using the 10 nearest neighbors as spatial weights. In 1983, as shown in Figure 2a, significant clusters or outliers are mostly missing. Only one cluster of spatial co-inventive cores appears in the Midwest, concentrated on St. Louis and St. Joseph (Missouri), Iowa City and Des Moines (Iowa), Lafayette (Indiana), and Madison (Wisconsin). These co-inventive cores are intensely connected to medical research and practice, particularly novel technologies for preventing bacteria. These cores have surrounding cities classified as low co-inventive islands, including Toledo and Dayton-Springfield (Ohio), Kokomo (Indiana), Columbia (Missouri), Lincoln and Omaha (Nebraska), and Sioux City (Iowa). A few co-inventive peripheries appear across the Southeast and the Intermountain West with focal cities in Dallas and Lubbock (Texas), Santa Fe (New Mexico), Flagstaff (Arizona), Shreveport-Bossier City (Louisiana), Auburn-Opelika (Alabama), Tallahassee (Florida), Boise City (Idaho), and Billings (Montana). They are minor in the U.S. inter-city network of co-invention.

(a)

(a) 1983

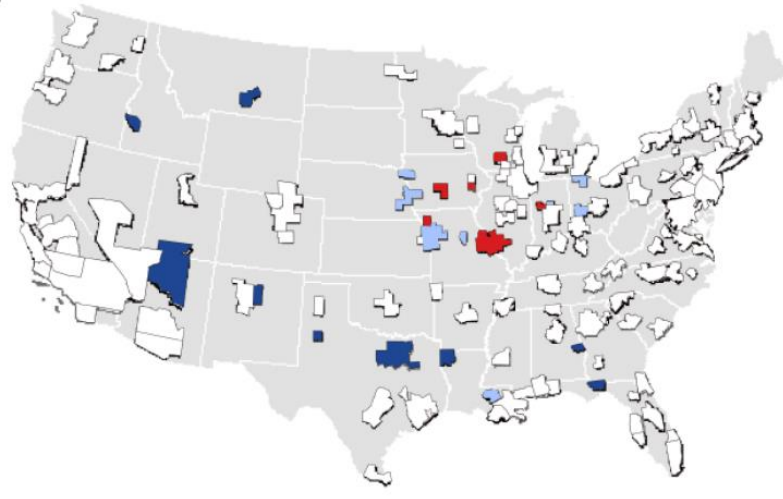

(b)

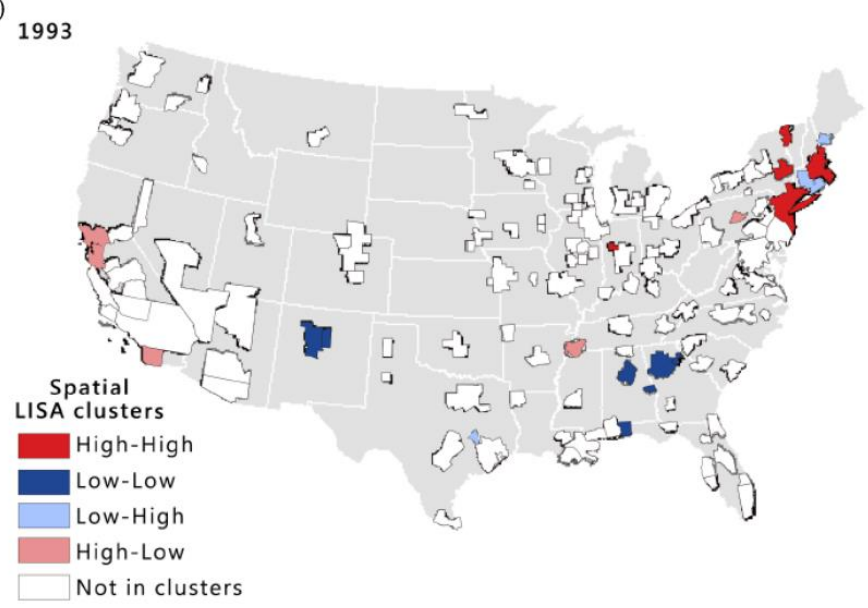

Figure 2. Spatial LISA (local indicators of spatial association) cluster maps in 150 cities, (a) 1983 and (b) 1993. 
Figure $2 \mathrm{~b}$ shows the 1993 spatial LISA clusters map. A distinct group of co-inventive cores is evident in the Northeast, centered on New York and Albany-Schenectady-Troy (New York), Boston, New Haven (Connecticut), and Burlington (Vermont). Co-inventive activities in these core cities are mostly tied to pharmaceutical technologies, which are strongly related to spatial proximity. The finding corroborates the claim of Salazar et al. [101] that inter-city relationships are essential in the pharmaceutical industry. Clinical trials and drug development rely on high performance and economy of scale, which are only available in large firms located in a few major centers [24]. Some low co-inventive islands also occur in this region including Portland (Maine), Springfield (Massachusetts), Hartford (Connecticut), and Providence (Rhode Island). In the West, San Diego and San Francisco are two noticeable cities identified as high co-inventive islands. Both cities have high co-patenting rates, but their spatial neighbors are far less engaged in biotechnology co-inventing. Memphis (Tennessee) and State College (Pennsylvania) also join the list of high co-inventive islands. A sizable medical center in the former and a large public university in the latter lead to unusually high co-patenting rates compared with their nearest neighbors.

Figure 3 depicts the 2003 and 2013 spatial LISA cluster maps. In 2003, as shown in Figure 3a, San Diego and San Francisco remain as noticeable high co-inventive islands in the West. Some distinctive co-inventive peripheries are evident in the Southeast. These focal cities are Jackson (Mississippi), Mobile (Alabama), New Orleans (Louisiana), and Pensacola (Florida). Figure 3b shows the 2013 spatial LISA cluster map. Only one small co-inventive core appears in St. Joseph (Missouri). San Diego and San Francisco are still categorized as high co-inventive islands, along with Rochester (New York) and Gainesville (Florida). A group of spatial co-inventive peripheries in the Southeast observably enlarge, spreading from Florida to east Texas. Several co-inventive cores are identified in the Midwest, including Rochester (Minnesota), St. Louis, Iowa City, and Lafayette.

(a)

2003

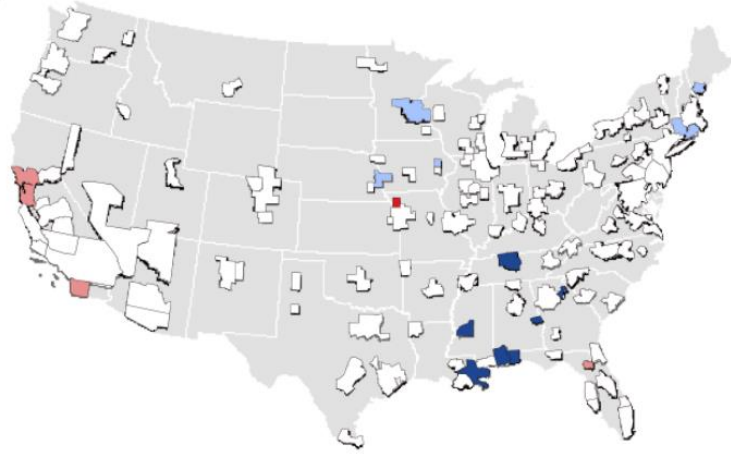

(b) 2013

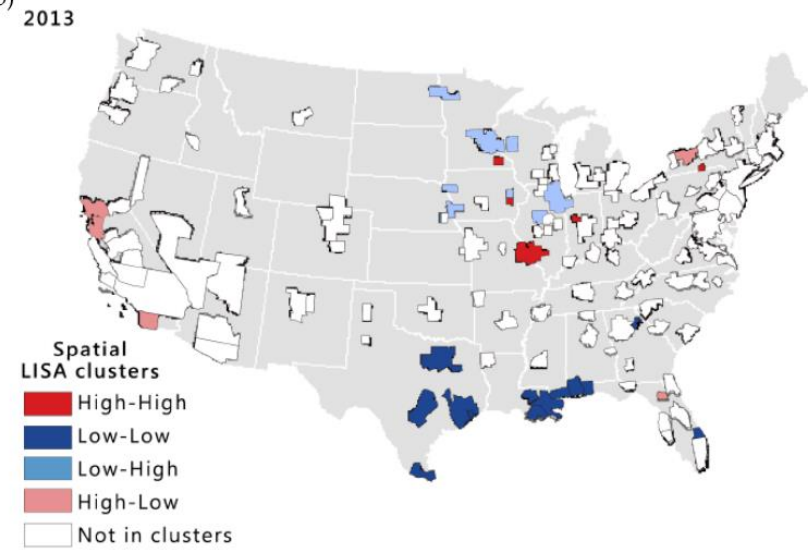

Figure 3. Spatial LISA (local indicators of spatial association) cluster maps in 150 cities, (a) 2003 and (b) 2013 . 


\subsubsection{Network Proximity}

Network proximity of inventors' co-patenting ties offers an alternative view on the properties of inter-city systems of co-invention. It is important to note that when interpreting network proximity, one should look at the neighboring structure from its network weights matrix to determine the dependence of each city on others. Distant cities can be closely tied in the inter-city system, while nearby areas may have little network proximity. The network weights matrix of each year is constructed by the annual frequency of co-patenting ties between inventors located in any two connecting cities.

The network LISA cluster maps illustrate that the patterns of network proximity are largely composed of low co-inventive islands, along with a few co-inventive cores. Figure 4 shows the network LISA cluster maps in 1983 and 1993. A majority of co-patenting ties are localized, as $82.9-77.5 \%$ of ties occur within the same city (see Table 1 for details). Figure 4a shows the 1983 spatial LISA cluster map. Raleigh-Durham is categorized as the only co-inventive core and it has two distant neighbors (partner-cities)-San Francisco and Cincinnati. In 1993, as a growing number of inventors join inter-city co-patenting ties, more discernible co-inventive cores have emerged. Figure $4 \mathrm{~b}$ shows the 1993 network LISA cluster map. New York, collaborating with almost 40 partner-cities, is the national co-inventive core. Detroit-Ann Arbor (Michigan) and Indianapolis (Indiana) are the other two distinct co-inventive cores with each having nine partner-cities. Figure 5 shows that Detroit-Ann Arbor and Indianapolis have different types of neighboring structures. The former is strongly related to Boston, New York, and Philadelphia, as well as neighboring Lansing-East Lansing (Michigan) and Cincinnati (Ohio), while the latter (Indianapolis) is primarily tied to New York, Washington D.C.-Baltimore, and Cincinnati, as well as Austin (Texas) and New Orleans (Louisiana) in the South. Seattle and Houston (Texas) are also categorized as co-inventive cores. Seattle is mainly associated with San Francisco, while Houston is relationally close to Philadelphia. These results indicate that the network proximity has regional biases.

Figure 6 shows the network LISA cluster maps in 2003 and 2013. The former (2003), as shown in Figure 6a, depicts that San Francisco and Boston are two national leading co-inventive cores where many partner-cities align their resources with the two centers for biotechnology co-invention. Both cores have strong connections with each other and their inventors are obviously network dependent. However, they have different types of network configurations. San Francisco is extensively engaged in co-patenting with nationwide biotechnology centers including New York, San Diego, Los Angeles, and Washington D.C.-Baltimore. In contrast, Boston's major partner-cities are largely concentrated in the Northeast including New York, Philadelphia, Washington D.C.-Baltimore, and Providence (Rhode Island). Figure 7 shows another noticeable difference in network proximity with regional biases. Inventors located in Indianapolis and New London tend to primarily team up with inventors in the Midwestern cities (i.e., Chicago, Lafayette, Bloomington) and the Northeastern cities (i.e., Boston, New Haven, Hartford, Providence), respectively, while inventors located in Seattle and Denver have mostly national ties. Network proximity with regional bias also occurs in some small co-inventive cores. State College (Pennsylvania) has a high degree of co-patenting with several Northeastern partner-cities (e.g., Boston, Philadelphia, Washington D.C.-Baltimore), and Kalamazoo-Battle Creek (Michigan) has its strongest ties with some Midwestern partner-cities (e.g., Chicago and Grand Rapids). In contrast, Lawrence (Kansas) widely cooperates with New York and San Francisco. Bryan-College Station (Texas) has partner-cities including Gainesville (Florida), Knoxville (Tennessee), and Washington D.C.-Baltimore. 
(a)

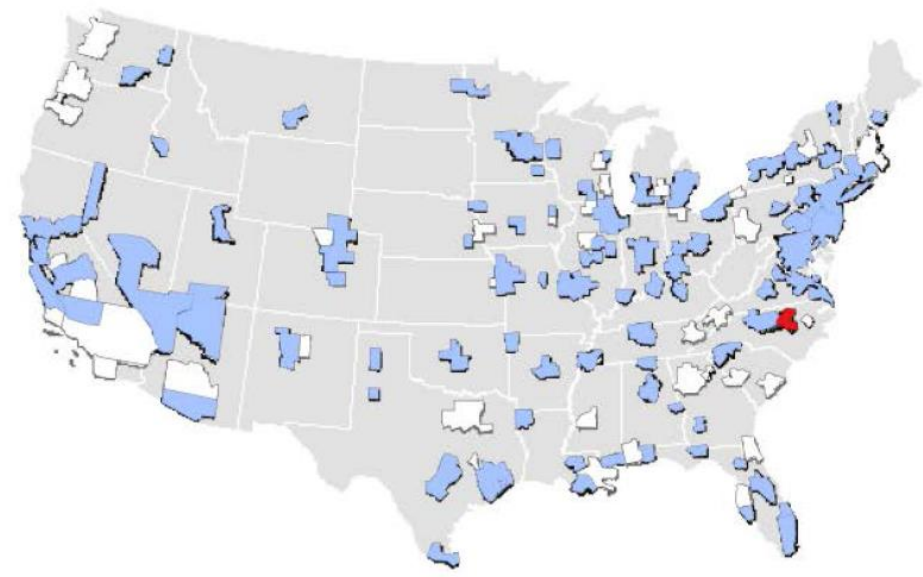

(b)

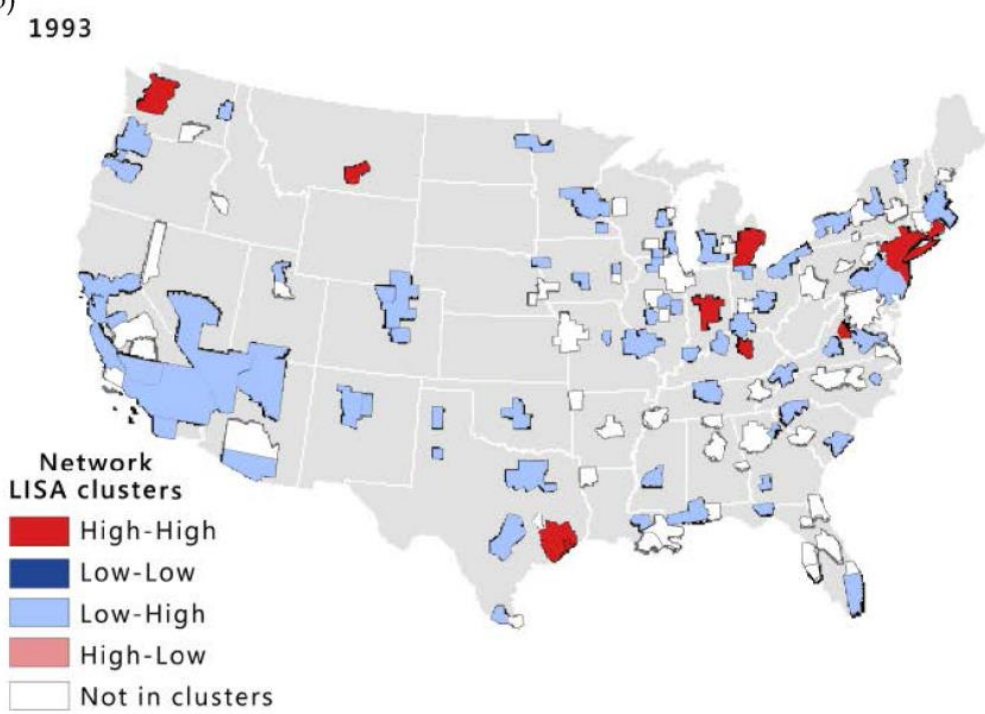

Figure 4. Network LISA (local indicators of spatial association) cluster maps in 150 cities, (a) 1983 and (b) 1993.

Figure 6b shows the 2013 network LISA cluster map. Major network co-inventive cores include San Francisco, New York, Washington D.C.-Baltimore, Denver, Raleigh-Durham, Boston, and Seattle. A few medium-sized cities are also identified as co-inventive cores including several university towns such as Purdue University at Lafayette, University of Iowa at Iowa City, Colorado State University at Fort Collins, Michigan State University at Lansing-East Lansing, University of Kentucky at Lexington, Illinois State University at Bloomington-Normal, and Texas A\&M University at College Station. In addition, Santa Fe (New Mexico), with its large national laboratory (i.e., Los Alamos National Laboratory) and research center (i.e., Santa Fe Institute); New London with a group of pharmaceutical firms; and Rochester (Minnesota) known as a 'Med City' with the headquarters of Mayo Clinic, all belong to the network of co-inventive cores. These cities and their partner-cities all have high co-patenting rates. The findings are consistent with the argument that biotechnology firms have largely concentrated around major universities and research centers [4,16,73,78-80]. Anselin et al. [4] concluded that universities and research institutions play a central role of knowledge exchange, not only as producers of fundamental research, but also by developing human capital in the form of high-skilled labor. Small and medium-sized co-inventive cores identified here also have these two essential requirements for biotechnology invention. 

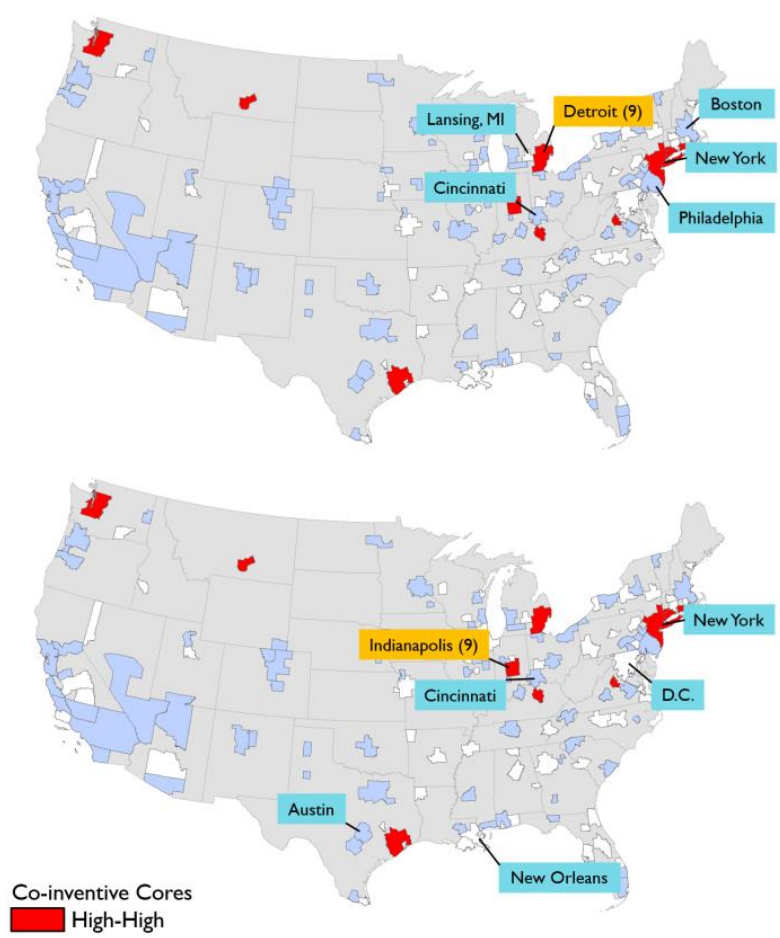

Figure 5. Comparison of Detroit and Indianapolis's closest network partners, 1993.

(a) 2003

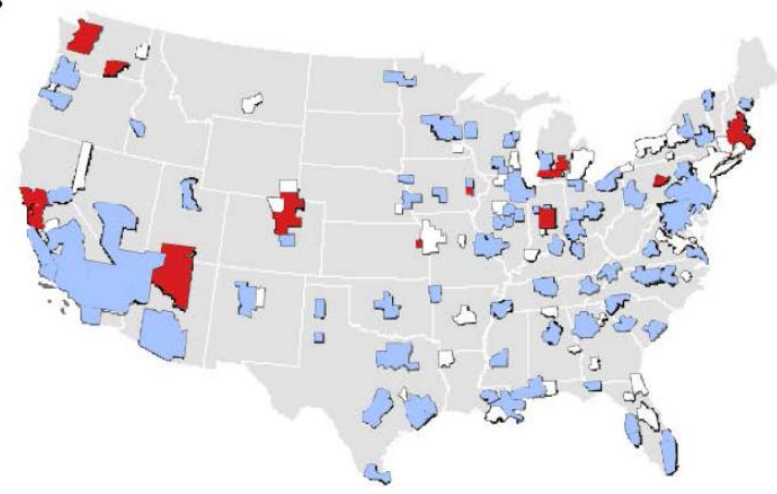

(b) 2013

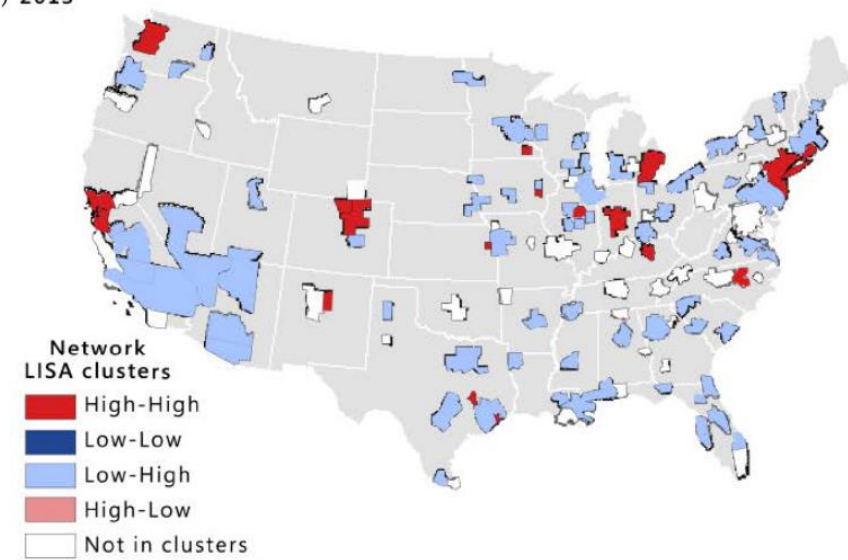

Figure 6. Network LISA (local indicators of spatial association) cluster maps in 150 cities, (a) 2003 and (b) 2013. 


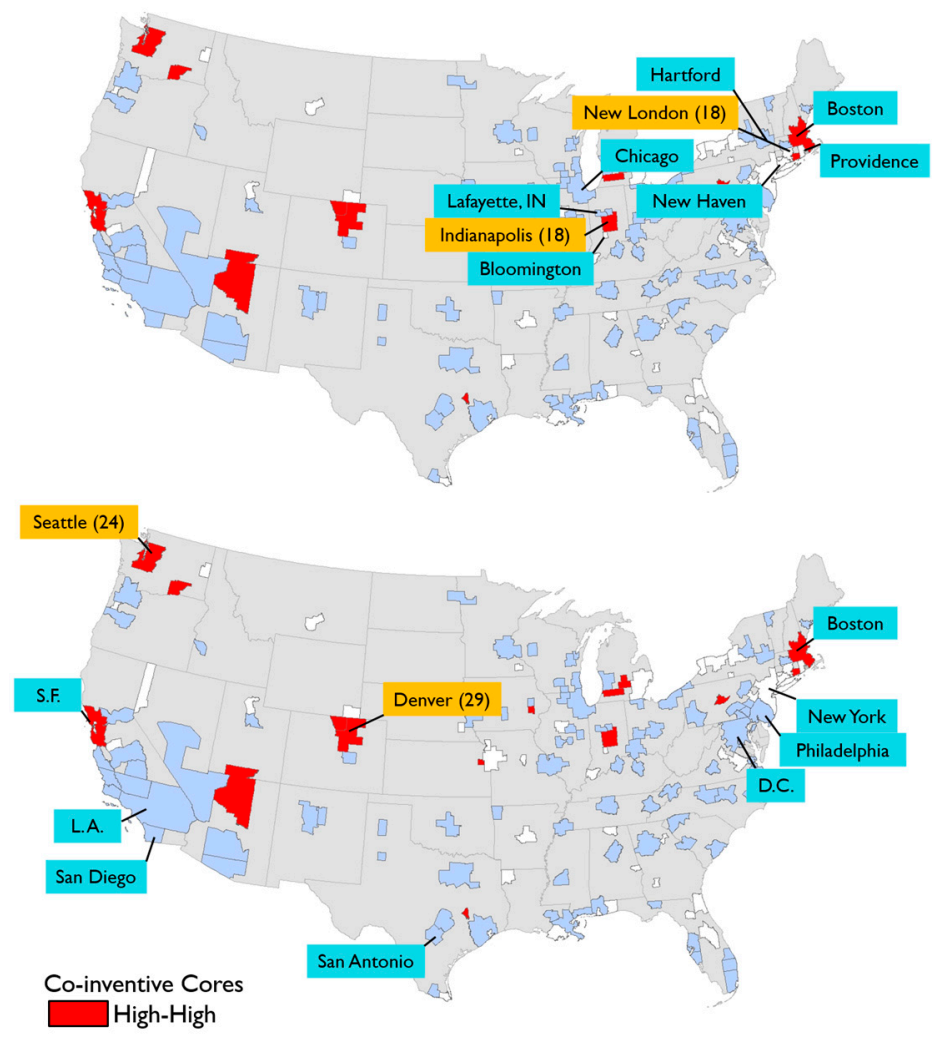

Figure 7. Comparison of New London and Indianapolis with Denver and Seattle's closest network partners, 2003.

\subsubsection{Comparison of Spatial and Network Proximity}

Over the course of the 30-year period, the inter-city co-invention gradually becomes more apparent, explicit, and identifiable to the network-based system. Both types of LISA cluster maps suggest that inventors' co-patenting is dissimilar when network and spatial dependencies are compared. Network proximity better defines the biotechnology co-patenting structures in the U.S. cities. The 2013 spatial LISA cluster map fails to discriminate observable spatial dependencies. San Diego and San Francisco in the West are the leading high co-inventive islands. The realm of co-inventive peripheral cities extends from Florida to east Texas. In contrast, the 2013 network LISA cluster map reveals a few distinctive co-inventive cores, while most cities are less involved in co-patenting. Biotechnology co-patenting ties in major centers mostly display their network associations as having regional biases, while a national-level space of knowledge exchange emerges. Figure 8 illustrates the evidence of regional effects. New York and San Francisco overpower the American inter-city system. Their collaborators span broadly across more than 70 cities. New York's strongest partner-cities are mainly concentrated in the East including Philadelphia, Washington D.C.-Baltimore, Boston, Hartford, and New Haven. New York is also strongly tied to San Francisco but its links with Los Angeles and San Diego are relatively weak. However, San Francisco's strongest partner-cities are New York, Washington D.C.-Baltimore, Philadelphia, Boston, Los Angeles, and San Diego. The network associations are truly national. Seattle and Raleigh also show a network proximity with regional biases. Seattle's co-inventive partners span 40 cities, but it is most closely related to San Diego, Los Angeles, and San Francisco. However, Raleigh's closest cities are relatively dispersed. These findings all indicate that the inter-city co-invention among American major centers is mostly regional and sometimes national, but rarely local. Spatial proximity is gradually less important for inter-city co-invention compared with network proximity. 

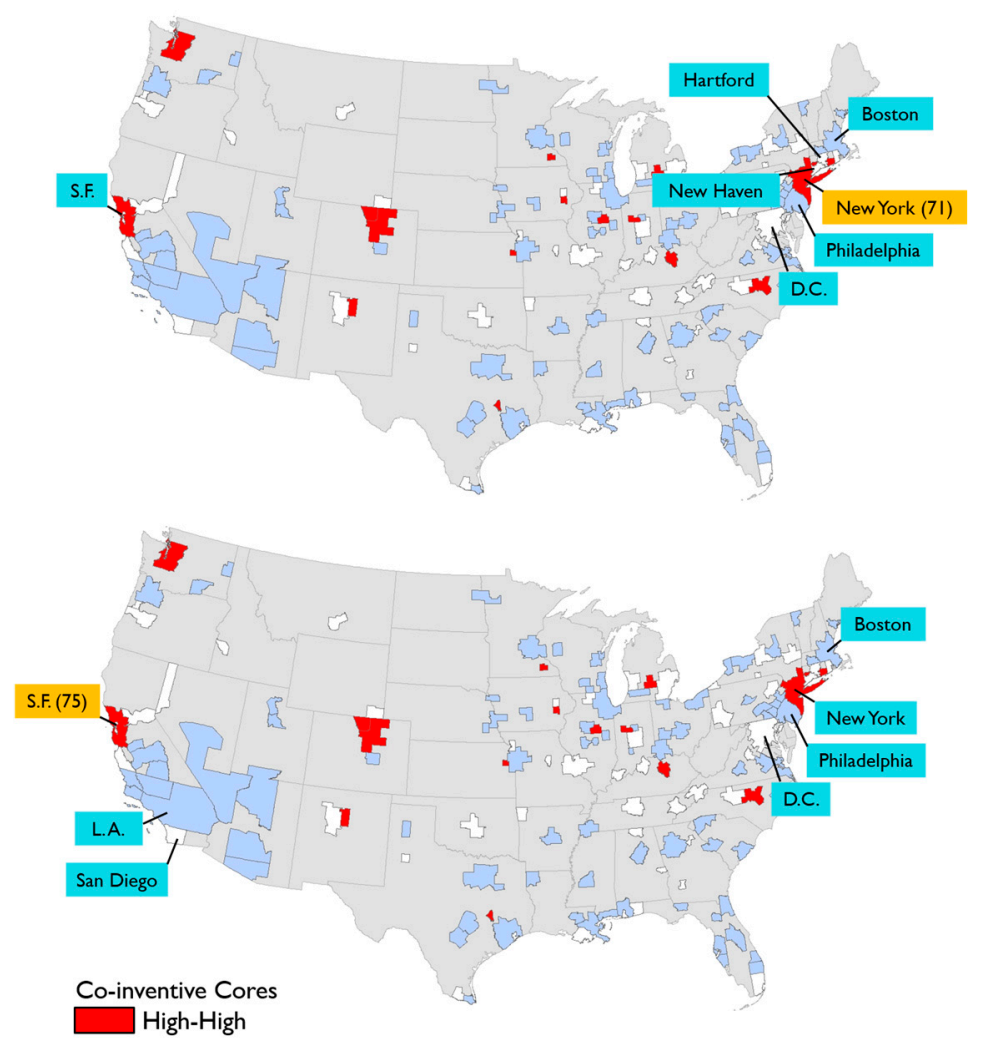

Figure 8. Comparison of San Francisco with New York's closest network partners, 2013.

\section{Conclusions}

The theory of localized knowledge spillovers argues that distance-based clustering of agents is an anchor in the geography of invention [1-5]. Tacit information and knowledge flows are concentrated in space because personal learning and sharing rely heavily on face-to-face interaction $[55,56]$. However, information exchanges also occur in long-distance and wide-ranging networks of collaboration through formal and informal relationships [6-10]. Creative firms build and sustain external and internal resources that can develop resilience capacity to minimize the effects of disasters and reduce economic losses [30,33,35]. Balland et al. [70] and Huggins and Thompson [102] argued that successful inventors might have better knowledge relationships with local inventors, but also with inventors outside the cluster. Combining local and extra-local competencies and skills to develop an inter-city system is considered a major strategy for cities to mitigate and adapt to climate change and economic recession, which in turn provides a way to build urban resilience $[19,20,26,28]$. Connections among inventors in different cities can serve as channels for new ideas and alternative perspectives, allowing a city to build its urban resilience. However, little attention in the literature of urban resilience has been given to the structural properties of networks, and few empirical studies have yet been conducted in this area, especially in American cities.

This article builds on the prior research by updating the database from 1983 to 2013 with a 10-year interval. It also extends the analysis by examining the relative importance of the network compared with spatial proximity in U.S. inter-city relationships. The objective is to share some insights into the evolutionary perspective of American inter-city networks of co-invention, which provides useful information on the structural conditions of networks for urban resilience. Biotechnology co-patenting involving increasing knowledge exchange and inter-city collaboration is investigated using exploratory spatial data analysis (ESDA) and social network analysis.

Results of the global Moran's I reveal that only the 2013 network-based system shows a statistically significant but negative statistic, indicating that the U.S. cities with low co-patenting rates are network 
associated with major co-inventive centers. This evidence suggests that network proximity is developing in the inter-city system by connecting both major centers and minor cities. As compared with my previous report [25], the significant and negative statistic indicates that the 2013 network proximity supports Barabási [99] and Cattani and Ferriani's [100] argument that a trend of co-inventive cores underpins peripheral development. The U.S. inter-city network of co-invention in 2013 is shifting towards becoming more resilient and sustainable. Biotechnology core centers establish norms and conventions that inspire collective sharing and learning, while peripheral cities provide possible recruits who could access and absorb new ideas and fresh perspectives in order to prompt rapid adaptation and avoid negative lock-in [19,20,24,35,42].

Results of the spatial LISA cluster maps reveal few distinguishable spatial associations in any of the years of analysis. While significant spatial LISA clusters or outliers are mostly missing in 1983, some co-inventive core cities occur in the Midwest, including St. Louis and St. Joseph (Missouri), Iowa City and Des Moines (Iowa), Lafayette (Indiana), and Madison (Wisconsin). These core cities are highly connected to medical research and practice, particularly novel technologies for preventing bacteria, while a few low co-inventive islands are also classified around this region. In 1993, a distinct spatial group of co-inventive cores occurs in the Northeast centered on New York, Boston, Albany-Schenectady-Troy, New Haven, and Burlington. Cities in these cores are strongly related in spatial proximity and they are closely tied to pharmaceutical technologies. Drug development and clinical trials strongly rely on high performance and economy of scale, which are only available in large firms located in a few major centers [24]. This finding is consistent with the claim of Salazar et al. [101] that spatial inter-city relationships are essential in the pharmaceutical industry. San Diego and San Francisco in the West are two noticeable new appearances identified as high co-inventive islands, along with Memphis (Tennessee) and State College (Pennsylvania). In 2003, San Diego and San Francisco remain as noticeable high co-inventive islands, while some distinctive co-inventive peripheries are evident in the Southeast including Jackson (Mississippi), Mobile (Alabama), New Orleans (Louisiana), and Pensacola (Florida). In 2013, the spatial LISA cluster map only shows that only one small co-inventive core appeared in St. Joseph (Missouri). San Diego and San Francisco are still categorized as high co-inventive islands, along with Rochester (New York) and Gainesville (Florida). A group of spatial co-inventive peripheries in the Southeast observably enlarge, spreading from Florida to east Texas, compared with 10 years ago.

Results of the network LISA cluster maps reveal that a few cities have emerged as co-inventive cores with noticeable ties to distant partner-cities, but some regional biases are also identified. In 1983, a majority of co-patenting ties are conducted by local inventors and co-patenting activities are mainly localized within the same city. Raleigh-Durham is categorized as the only co-inventive core. In 1993, as more inventors join inter-city co-patenting, more discernible co-inventive cores emerge. New York is the primary core of biotechnology co-invention. Detroit-Ann Arbor, Indianapolis, Seattle, and Houston are the other distinct co-inventive cores; however, they have different types of neighboring structures indicating the network proximity has regional biases. In 2003, San Francisco and Boston are two national leading co-inventive cores, but their network configurations are required different. The former is extensively engaged in co-patenting with nationwide biotechnology centers. In contrast, the latter's major partner-cities are largely concentrated in the Northeast. The differences of network proximity with regional biases are also evident in some small and medium-sized cities. In 2013, major network co-inventive cores include San Francisco, New York, Washington D.C.-Baltimore, Denver, Raleigh-Durham, Boston, and Seattle. A few medium-sized university towns are also identified as co-inventive cores. These cities and their partner-cities all have high co-patenting rates. These findings are consistent with the argument of Cooke [16], Audretsch [73], and Niosi and Banik [80] that biotechnology firms have largely concentrated around major universities and research centers.

In this article, I conduct an empirical study to examine the relative importance of the network compared with spatial proximity in U.S. inter-city networks of co-invention from 1983 to 2013. In the analysis of the 30-year period, the contributions are twofold. First, the evolutionary evidence of the U.S. inter-city structure gradually becomes more explicit, apparent, and identifiable in the 
network-based system. Network proximity better defines the biotechnology co-patenting relationships among the U.S. cities, compared with spatial proximity. The current inter-city networks of co-invention among the U.S. cities are mostly regional, with some national but few local ties. Major co-inventive centers occupy pivotal positions in the inter-city system, allowing them to influence the entire network and to control knowledge flows throughout the system. Second, the current inter-city network of co-invention shows that the cores establish norms and conventions and the peripheries provide possible recruits who are able to access and absorb new ideas and fresh perspectives. The structure provides a way to develop climate change mitigation and adaptation policies for disasters or economic recessions. This article tracks co-patenting ties in the networks to account for bilateral knowledge flows between cities, but the directionality of connections is disregarded. Future research should attempt to distinguish between the incoming and outgoing knowledge flows of each node in the system. I also ignore connections to cities in other countries. My original patent data show that American biotechnology heavily relies on global sources of knowledge. Co-invention could span international territories. Since the impacts of climate change are global in scope and unprecedented in scale, analysis of global collaboration in biotechnology or other technologies is clearly needed both to understand the changing properties of the network and the functions of world cities.

Conflicts of Interest: The author declares no conflict of interest.

\section{References}

1. Jaffe, A.B. Real effects of academic research. Am. Econ. Rev. 1989, 79, 957-967.

2. Acs, Z.J.; Audretsch, D.B.; Feldman, M.P. RD spillovers and recipient firm size. Rev. Econ. Stat. 1994, 76, 336-340. [CrossRef]

3. Audretsch, D.B.; Feldman, M.P. RD spillovers and the geography of innovation and production. Am. Econ. Rev. $1996,86,630-652$.

4. Anselin, L.; Varga, A.; Acs, Z.J. Local geographic spillovers between university research and high technology innovations. J. Urban Econ. 1997, 42, 422-448. [CrossRef]

5. Autant-Bernard, C. Science and knowledge flows: Evidence from the French case. Res. Policy 2001, 30, 1069-1078. [CrossRef]

6. Rondé, P.; Hussler, C. Innovation in regions: What does really matter? Res. Policy 2005, 34, 1150-1172. [CrossRef]

7. Maggioni, M.A.; Nosvelli, M.; Uberti, T.E. Space versus networks in the geography of innovation: A European analysis. Pap. Reg. Sci. 2007, 86, 471-493. [CrossRef]

8. Knoben, J. Localized inter-organizational linkages, agglomeration effects, and the innovative performance of firms. Ann. Reg. Sci. 2009, 43, 757-779. [CrossRef]

9. Wilhelmsson, M. The spatial distribution of inventor networks. Ann. Reg. Sci. 2009, 43, 645-668. [CrossRef]

10. Huber, F. Do clusters really matter for innovation practices in information technology? Questioning the significance of technological knowledge spillovers. J. Econ. Geogr. 2012, 12, 107-126. [CrossRef]

11. Amin, A.; Cohendet, P. Architectures of Knowledge: Firms, Capabilities and Communities; Oxford University Press: Oxford, UK, 2004; pp. 465-489.

12. Amin, A.; Cohendet, P. Geographies of knowledge formation in firms. Ind. Innov. 2005, 12, 465-486. [CrossRef]

13. Breschi, S.; Lissoni, F. Mobility and Social Networks: Localized Knowledge Spillovers Revisited; CESPRI Working Paper 142; Universitá Bocconi: Milano, Italy, 2003.

14. Gertler, M.S.; Levitte, Y.M. Local nodes in global networks: The geography of knowledge flows in biotechnology innovation. Ind. Innov. 2005, 12, 487-507. [CrossRef]

15. Birch, K. Knowledge space and biotechnology. Geogr. Compass 2007, 1, 1097-1117. [CrossRef]

16. Cooke, P. Global bioregional networks: A new economic geography of bioscientific knowledge. Eur. Plan. Stud. 2006, 14, 1265-1285. [CrossRef]

17. Ponds, R.; von Oort, F.; Frenken, K. The geographical and institutional proximity of research collaboration. Pap. Reg. Sci. 2007, 86, 423-443. [CrossRef] 
18. Bathelt, H.; Malmberg, A.; Maskell, P. Clusters and knowledge: Local buzz, global pipelines and the process of knowledge creation. Prog. Hum. Geogr. 2004, 28, 31-56. [CrossRef]

19. Asheim, B.T.; Isaksen, A. Regional innovation systems: The integration of local 'sticky' and global 'ubiquitous' knowledge. J. Technol. Transf. 2002, 27, 77-86. [CrossRef]

20. Boschma, R. Proximity and innovation: A critical assessment. Reg. Stud. 2005, 39, 61-74. [CrossRef]

21. Balland, P.A. Proximity and the evolution of collaboration networks: Evidence from research and development projects within the Global Navigation Satellite System (GNSS) industry. Reg. Stud. 2012, 46, 741-756. [CrossRef]

22. Broekel, T.; Boschma, R.A. Knowledge networks in the Dutch aviation industry: The proximity paradox. J. Econ. Geogr. 2012, 12, 409-433. [CrossRef]

23. Balland, P.A.; De Vaan, M.; Boschma, R. The dynamics of interfimr networks along the industry life cycle: The case of the global video game industry, 1987-2007. J. Econ. Geogr. 2013, 13, 741-765. [CrossRef]

24. Ó hUallacháin, B.; Lee, D.-S. Urban centers and networks of co-invention in American biotechnology. Ann. Reg. Sci. 2014, 52, 799-824. [CrossRef]

25. Lee, D.-S. Investigating network-based proximity in American biotechnology. Procedia Comput. Sci. 2015, 60, 1021-1031. [CrossRef]

26. Balland, P.A.; Rigby, D.; Boschma, R. The technological resilience of US cities. Camb. J. Reg. Econ. Soc. 2015, 8, 167-184. [CrossRef]

27. Balland, P.A.; Rigby, D. The geography of complex knowledge. Econ. Geogr. 2017, 93, 1-23. [CrossRef]

28. Tyler, S.; Moench, M. A framework for urban climate resilience. Clim. Dev. 2012, 4, 311-326. [CrossRef]

29. Bristow, G. Resilient regions: Re-'place'ing regional competitiveness. Camb. J. Reg. Econ. Soc. 2010, 3, $153-167$. [CrossRef]

30. Christopherson, S.; Michie, J.; Tyler, P. Regional resilience: Theoretical and empirical perspectives. Camb. J. Reg. Econ. Soc. 2010, 3, 3-10. [CrossRef]

31. Diodato, D.; Weterings, A.B.R. The resilience of regional labour markets to economic shocks: Exploring the role of interactions among firms and workers. J. Econ. Geogr. 2015, 4, 723-742. [CrossRef]

32. Martin, R.; Sunley, P. On the notion of regional economic resilience: Conceptualization and explanation. J. Econ. Geogr. 2015, 15, 1-42. [CrossRef]

33. Cho, R.; Hassink, P. Limits to locking-out through restructuring: The textile industry in Daegu, South Korea. Reg. Stud. 2009, 43, 1183-1198. [CrossRef]

34. Grabher, G. The weakness of strong ties: The lock-in of regional development in the Ruhr area. In The Embedded Firm: On the Socioeconomics of Industrial Networks; Grabher, G., Ed.; TJ Press: London, UK, 1993; pp. 255-278.

35. Boschma, R. Towards an evolutionary perspective on regional resilience. Reg. Stud. 2015, 49, 733-751. [CrossRef]

36. Wrigley, N.; Dolega, L. Resilience, fragility, and adaptation: New evidence on the performance of UK high streets during global economic crises and its policy implications. Environ. Plan. A 2011, 43, 2337-2363. [CrossRef]

37. Hassink, R. How to unlock regional economies from path dependency? Eur. Plan. Stud. 2005, 13, 521-535. [CrossRef]

38. Hassink, R. The strength of weak lock-ins: The renewal of the Westmünsterland textile industry. Environ. Plan. A 2007, 39, 1147-1165. [CrossRef]

39. Hassink, R. Locked in decline? On the role of regional lock-ins in old industrial areas. In Handbook of Evolutionary Economic Geography; Boschma, R., Martin, R., Eds.; Edward Elgar: Cheltenham, UK, 2010; pp. 450-468.

40. Simmie, J.; Martin, R. The economic resilience of regions: Towards an evolutionary approach. Camb. J. Reg. Econ. Soc. 2010, 3, 27-43. [CrossRef]

41. Bristow, G.; Porter, J.; Cooke, P. Path Interdependence, Firm Innovation and Resilience. A Complex Adaptive System Perspective; CASS Working Paper; Cardiff University: Cardiff, UK, 2012.

42. Crespo, J.; Suire, R.; Vicente, J. Lock-in or lock-out? How structural properties of knowledge networks affect regional resilience. J. Econ. Geogr. 2014, 14, 199-219. [CrossRef]

43. Krätke, S. Regional knowledge networks: A network analysis approach to the interlinking of knowledge resources. Eur. Urban Reg. Stud. 2010, 17, 83-97. [CrossRef]

44. Coenen, L.; Moodysson, J.; Asheim, B.T. Nodes, networks and proximities: On the knowledge dynamics of the Medicon Valley biotech cluster. Eur. Plan. Stud. 2004, 12, 1003-1016. [CrossRef] 
45. Fontes, M. Distant networking: The knowledge acquisition strategies of 'out-cluster' biotechnology firms. Eur. Plan. Stud. 2005, 13, 899-920. [CrossRef]

46. Cantner, U.; Graf, H. The network of innovators in Jean: An application of social network analysis. Res. Policy 2006, 35, 463-480. [CrossRef]

47. Casper, S. How do technology clusters emerge and become sustainable? Social network information and inter-firm mobility within the San Diego technology cluster. Res. Policy 2007, 36, 438-455. [CrossRef]

48. Eisingerich, A.B.; Bell, S.J.; Tracey, P. How can clusters sustain performance? The role of network strength, network openness, and environmental uncertainty. Res. Policy 2010, 39, 239-253. [CrossRef]

49. Owen-Smith, J.; Powell, W.W. Knowledge networks as channels and conduits: The effects of spillovers in the Boston biotechnology community. Organ. Sci. 2004, 15, 5-21. [CrossRef]

50. Feldman, M.P. Where science comes to life: University bioscience, commercial spin-offs, and regional economic development. J. Comp. Policy Anal. Res. Pract. 2001, 2, 345-361. [CrossRef]

51. Breschi, S.; Lissoni, F. Knowledge Network from Patent Data: Methodological Issues and Research Targets; CESPRI Working Paper 150; Universitá Bocconi: Milano, Italy, 2004.

52. Lobo, J.; Strumsky, D. Metropolitan patenting, inventor agglomeration and social networks: A tale of two effects. J. Urban Econ. 2008, 63, 871-884. [CrossRef]

53. Almeida, P.; Kogut, B. Localization of knowledge and the mobility of engineers in regional network. Manag. Sci. 1999, 45, 905-917. [CrossRef]

54. Nelson, R.P.; Winter, S.G. An Evolutionary Theory of Economic Change; Harvard University Press: Cambridge, MA, USA, 1982; p. 183.

55. Maskell, P.; Malmberg, A. Localised learning and industrial competitiveness. Camb. J. Econ. 1999, 23, 167-185. [CrossRef]

56. Gertler, M.S. Tacit knowledge in production system: How important is geography? In The Economic Geography of Innovation; Polenske, K.P., Ed.; Cambridge University Press: New York, NY, USA, 2007; pp. 87-111.

57. Acs, Z.J.; Audretsch, D.B.; Feldman, M.P. Real effects of academic research: Comment. Am. Econ. Rev. 1992, 82, 363-367.

58. Varga, A. Local academic knowledge spillovers and the concentration of economic activity. J. Reg. Sci. 2000, 40, 289-309. [CrossRef]

59. Jaffe, A.B.; Trajtenberg, M.; Henderson, R. Geographic localization of knowledge spillovers as evidenced by patent citations. Q. J. Econ. 1993, 108, 577-598. [CrossRef]

60. Thompson, P.; Fox-Kean, M. Patent citations and the geography of knowledge spillovers: A reassessment. Am. Econ. Rev. 2005, 95, 450-460. [CrossRef]

61. Storper, M. The Regional World: Territorial Development in a Global Economy; Guilford: New York, NY, USA, 1997; pp. 324-343.

62. Boggs, J.; Rantisi, N.M. The 'relational turn' in economic geography. J. Econ. Geogr. 2003, 3, 109-116. [CrossRef]

63. Sunley, P. Relational economic geography: A partial understanding or a new paradigm? Econ. Geogr. 2008, 84, 1-26. [CrossRef]

64. Yeung, H.W.-C. Rethinking relational economic geography. Trans. Inst. Br. Geogr. 2005, 30, 37-51. [CrossRef]

65. Gallaud, D.; Torre, A. Geographical proximity and the diffusion of knowledge. In Rethinking Regional Innovation; Fuchs, G., Shapira, P., Koch, A., Eds.; Springer: New York, NY, USA, 2004; pp. 234-245.

66. Autant-Bernard, C.; Mairesse, J.; Massard, N. Spatial knowledge diffusion through collaborative networks. Pap. Reg. Sci. 2007, 86, 341-350. [CrossRef]

67. Bathelt, H. Buzz-and-pipeline dynamics: Towards a knowledge-based multiplier model of clusters. Geogr. Compass 2007, 1, 1282-1298. [CrossRef]

68. Malmberg, A. Beyond the cluster-Local milieus and global connections. In Remarking the Global Economy: Economic-Geographical Perspectives; Peck, J., Yeung, H.W.-C., Eds.; Sage: London, UK, 2003; pp. 145-159.

69. Allen, J. Power/economic knowledge: Symbolic and spatial formations. In Knowledge, Space, Economy; Bryson, J., Daniels, P.W., Henry, N., Pollard, J., Eds.; Routledge: London, UK, 2000; pp. 15-33.

70. Balland, P.A.; Boschma, R.; Frenken, K. Proximity and innovation: From static to dynamics. Reg. Stud. 2015, 49, 907-920. [CrossRef]

71. Breschi, S.; Malerba, F. The geography of innovation and economic clustering: Some introductory notes. Ind. Corp. Chang. 2001, 10, 817-833. [CrossRef] 
72. Powell, W. Inter-organizational collaboration in the biotechnology industry. J. Inst. Theor. Econ. 1996, 152, 197-215.

73. Audretsch, D.B. The role of small firm in U.S. biotechnology clusters. Small Bus. Econ. 2001, 17, 3-15. [CrossRef]

74. Mckelvey, M. Evolutionary economics perspective on the regional-national-international dimensions of biotechnology innovations. Environ. Plan. C 2004, 22, 179-197. [CrossRef]

75. Vallance, P. Rethinking economic geographies of knowledge. Geogr. Compass 2007, 1, 797-813. [CrossRef]

76. Augustine, N.; Wolman, H.; Wial, H.; McMillen, M. Regional Economic Capacity, Economic Shocks, and Economic Resilience; MacArthur Foundation Network on Building Resilient Regions Working Paper; Building Resilient Regions: Washington, DC, USA, 2013.

77. Torre, A.; Rallet, A. Proximity and localization. Reg. Stud. 2005, 39, 47-59. [CrossRef]

78. Saxenian, A.; Hsu, J.-Y. The Silicon Valley-Hsinchu connection: Technical communities and industrial upgrading. Ind. Corp. Chang. 2001, 10, 893-920. [CrossRef]

79. Kenney, M.; Nelson, A.; Patton, D. The university-centric high-tech cluster of Madison, United States. In Clusters, Innovation and Entrepreneurship; Miranda, G., Potter, J., Eds.; OECD: Paris, France, 2009; pp. 167-192.

80. Niosi, J.; Banik, M. The evolution and performance of biotechnology regional systems in innovation. Camb. J. Econ. 2005, 29, 343-357. [CrossRef]

81. Cassi, L.; Morrison, A. Social Networks and Innovation: Concepts, Tools, and Recent Empirical Contribution; Working Paper 59; Dinamia: Lisboa, Portugal, 2007.

82. Agrawal, A.; Cockburn, I.; McHale, J. Gone but not forgotten: Knowledge flows, labor mobility, and enduring social relationships. J. Econ. Geogr. 2006, 6, 571-591. [CrossRef]

83. Polanyi, M. The logic of tacit inference. Philosophy 1966, 41, 1-18. [CrossRef]

84. Adelman, D.E.; DeAngelis, K.L. Patent Metrics: The Mismeasure of Innovation in the Biotech Patent Debate; Arizona Legal Studies Discussion Paper No. 06-10; The University of Arizona: Tucson, AZ, USA, 2007.

85. US Bureau of Economic Analysis (BEA) Sources of Regional Data. Available online: https://www.bea.gov / iTable/iTable.cfm?ReqID=70\&step=1\#reqid=70\&step=1\&isuri=1 (accessed on 23 April 2015).

86. Messner, S.F.; Anselin, L. Spatial analysis of homicide with areal data. In Spatial Integrated Social Science; Goodchid, M.F., Janelle, D., Eds.; Oxford University: New York, NY, USA, 2004; pp. 127-144.

87. Anselin, L.; Lozano, N.; Koschinsky, J. Rate Transformations and Smoothing; University of Illinois at Urbana-Champaign: Urbana, IL, USA, 2006.

88. Anselin, L. GeoDa 0.9.5-i Release Notes; University of Illinois at Urbana-Champaign: Urbana, IL, USA, 2004.

89. Anselin, L. Local indicators of spatial association-LISA. Geogr. Anal. 1995, 27, 93-115. [CrossRef]

90. Ó hUallacháin, B.; Lee, D.-S. Technological specialization and variety in urban invention. Reg. Stud. 2010, 45, 67-88. [CrossRef]

91. Hall, B.H.; Jaffe, A.B.; Trajtenberg, M. The NBER Patent Citation Data File: Lessons Insights and Methodological Tools; Working Paper 8498; National Bureau Economic Research: Cambridge, MA, USA, 2001.

92. Cortright, J.; Mayer, H. Signs of Life: The Growth of Biotechnology Centers in the U.S.; The Brookings Institution: Washington, DC, USA, 2002.

93. Hevesi, A.G.; Bleiwas, K.B. The Economic Impact of the Biotechnology and Pharmaceutical Industries in New York; Report 11-2005; Office of the State Comptroller: New York, NY, USA, 2005.

94. US Patent and Trademark Office (USPTO) Patent Full-Text and Image Database. Available online: http:/ / patft. uspto.gov/netahtml/PTO/srchnum.htm (accessed on 15 July 2015).

95. US Office of Management and Budget (OMB). Available online: https://www.census.gov/population/ estimates/metro-city/99mfips.txt (accessed on 20 March 2012).

96. Acs, Z.J.; Armington, C. Entrepreneurship, Geography, and American Economic Growth; Cambridge: New York, NY, USA, 2006; pp. 256-261.

97. Ejermo, O.; Karlsson, C. Interregional inventor networks as studied by patent coinventorships. Res. Policy 2006, 35, 412-430. [CrossRef]

98. Borgatti, S.P.; Everett, M.G.; Freeman, L.C. UCINET for Windows: Software for Social Network Analysis; Analytic Technologies: Harvard, MA, USA, 2002.

99. Barabási, A.I. Network theory-The emergence of the creative enterprise. Science 2005, 308, 639-641. [CrossRef] [PubMed]

100. Cattani, G.; Ferriani, S. A core/periphery perspective on individual creative performance: Social networks and cinematic achievements in the Hollywood film industry. Organ. Sci. 2008, 6, 824-844. [CrossRef] 
101. Salazar, A.; Hackney, R.; Howells, J. The strategic impact of internet technology in biotechnology and pharmaceutical firms: Insights from a knowledge management perspective. Inf. Technol. Manag. 2003, 4, 289-301. [CrossRef]

102. Huggins, R.; Thompson, P. A network-based view of regional growth. J. Econ. Geogr. 2014, 14, 511-545. [CrossRef] 